\title{
PERLINDUNGAN HUKUM TERHADAP PASIEN DI BIDANG PELAYANAN MEDIS BERDASARKAN KUH PERDATA
}

\author{
Suwarto \\ RSUD Gambiran Kota Kediri \\ Email: mizanjurnalilmuhukum@gmail.com
}

\begin{abstract}
ABSTRAK
Penelitian ini bertujuan untuk mengetahui substansi materi mengenai perlindungan hukum terhadap pasien di bidang pelayanan medis yang diatur dalam KUHPerdata serta bentuk perlindungan terhadap pasien di bidang pelayanan medis. Penelitian ini merupakan penelitian hukum normative atau doktrinal bersifat diskriptif, mengkaji perlindungan pasien sebagai konsumen dalam bidang pelayanan medis serta bentuk perlindungannya berdasarkan KUHPerdata. Sumber penelitian sekunder yang digunakan meliputi bahan hukum primer, bahan hukum sekunder, dan bahan hukum tersier. Teknik pengumpulan sumber penelitian yang digunakan yaitu studi kepustakaan dan rujukan internet. Analisis penelitian yang digunakan silogisme induktif yaitu dengan menarik kesimpulan dari kasus - kasus individual nyata untuk menjawab permasalahan yang diteliti. Tahap terakhir adalah menarik kesimpulan dari sumber penelitian yang diolah, sehingga pada akhirnya dapat diketahui mengenai perlindungan pasien sebagai konsumen jasa medis yang diatur dalam KUHPerdata serta bentuk perlindungan terhadap pasien konsumen jasa medis. Berdasarkan hasil penelitian dapat ditarik kesimpulan bahwa dalam dunia medis yang semakin berkembang, petugas atau tenaga medis (terutama dokter) sangat penting dalam menunjang kesehatan dari masyarakat dan diharapkan mampu memahami konsumennya secara keseluruhan. Dari tindakan medis tersebut tidak menutup kemungkinan terjadi suatu kesalahan ataupun kelalaian. Adanya kerugian tersebut, mendorong suatu pertanggungjawaban dari pihak yang merugikan pasien (tenaga / petugas medis) sebagai suatu bentuk perlindungan terhadap pasien bidang medis.

Kata Kunci:kerugian pasien, pelayanan medis, hukum perdata, perlindungan pasien, tanggungjawab tenaga / petugas medis (dokter)
\end{abstract}

\begin{abstract}
This research aims to find out the material substance about the law protection for the patient as the service consumer in medical service sector regulated in the Civil Code as well as the form of law protection for the patient as the service consumer in medical service sector. This study belongs to a normative or doctrinal law research that is descriptive in nature, studying the patient as the service consumer in medical service sector as well as the protection form based on the Civil Code. The secondary data source employed included primary, secondary and tertiary law research. Techniques of collecting research source were library study and internet reference. The data analysis was done using inductive syllogism technique, that is, to draw on a conclusion from individual real cases to answer the problem studied. The final step of research is to draw a conclusion from the research source process, so that finally it can be found the patient protection as the service consumer in medical service sector regulated in the Civil Code as well as the protection form. Considering the result of research, it can be concluded that medical sector increasingly develops; the physicians and medical officers (particularly doctor) are very important in supporting the society's health and expected to be able to understand their consumers entirely. The physicians given trust completely by the patient should consider the cost and benefit of action and always be cautious in implementing the medical action.

Keywords : code of civil law, medical services, patient loss, patient protection, physician accountability
\end{abstract}

\section{A. PENDAHULUAN}

Upaya peningkatan kualitas hidup manusia di bidang kesehatan, merupakan suatu usaha yang sangat luas dan menyeluruh, usaha tersebut meliputi peningkatan kesehatan masyarakat baik fisik maupun non fisik. Di dalam Sistem Kesehatan Nasional disebutkan, bahwa kesehatan menyangkut semua segi kehidupan yang ruang lingkup dan jangkauannya sangat luas dan kompleks.

Timbulnya hubungan antara pasien 
dengan dokter maupun pasien dengan pihak rumah sakit dapat dikarenakan pasien sangat mendesak untuk mendapatkan pertolongan. Dalam keadaan seperti ini pihak rumah sakit terutama dokter langsung melakukan apa yang disebut dengan zaakwaarneming, yaitu di mana seorang dengan sukarela tanpa mendapat perintah mewakili urusan orang lain hingga orang yang diwakili kepentingannya dapat menyelesaikan kepentingan tersebut, sebagaimana diatur dalam Pasal 1354 KUHPer, yaitu suatu bentuk hubungan hukum yang timbul bukan karena adanya "Persetujuan Tindakan Medis" terlebih dahulu.

Dalam pelayanan kesehatan, rumah sakit juga harus memperhatikan etika profesi tenaga yang bekerja di rumah sakit yang bersangkutan. Akan tetapi, tenaga profesional yang bekerja di rumah sakit dalam memberikan putusan secara profesional adalah mandiri. Putusan tersebut harus dilandaskan atas kesadaran, tanggung jawab dan moral yang tinggi sesuai dengan etika profesi masing-masing. Ditinjau dari segi ilmu kemasyarakatan dalam hal ini hubungan antara dokter dengan pasien menunjukkan bahwa dokter memiliki posisi yang dominant, sedangkan pasien hanya memiliki sikap pasif menunggu tanpa wewenang untuk melawan. Posisi demikian ini secara historis berlangsung selama bertahun - tahun, dimana dokter memegang peranan utama, baik karena pengetahuan dan ketrampilan khusus yang ia miliki, maupun karena kewibawaan yang dibawa olehnya karena ia merupakan bagian kecil masyarakat yang semenjak bertahun - tahun berkedudukan sebagai pihak yang memiliki otoritas bidang dalam memberikan bantuan pengobatan berdasarkan kepercayaan penuh pasien.

\section{Tujuan Penelitian}

Tujuan yang dikenal dalam suatu penelitian ada dua macam, yaitu tujuan obyektif yang berisikan mengetahui subtansi materi mengenai perlindungan hukum serta mengetahui bentuk perlindungan terhadap pasien sebagai konsumen jasa di bidang pelayanan medis yang diatur dalam KUHPerdata, dan tujuan subyektif yang berisikan untuk menambah wawasan serta pengetahuan bagi peneliti di bidang ilmu hukum baik teori maupun praktek dalam hal ini lingkup Hukum Perdata, dan menerapkan ilmu serta teori - teori hukum yang telah peneliti peroleh agar dapat memberi manfaat bagi peneliti sendiri khususnya dan masyarakat pada umumnya khususnya yang menyangkut Perlindungan Pasien sebagai konsumen jasa di bidang medis.

\section{B. METODE PENELITIAN}

Jenis penelitian yang akan digunakan dalam penulisan hukum ini adalah penelitian hukum normatif yaitu penelitian yang dilakukan dengan cara meneliti bahan pustaka atau data sekunder yang terdiri dari bahan hukum primer, bahan hukum sekunder, dan bahan hukum tersier dari masing - masing hukum normatif. Bahan - bahan tersebut disusun secara sistematis, dikaji, kemudian dibandingkan dan ditarik suatu kesimpulan dalam hubungannya dengan masalah yang diteliti.

Sifat Penelitian penelitian diskriptif, yang diartikan sebagai suatu prosedur pemecahan masalah yang diteliti pada saat sekarang berdasarkan fakta yang tampak atau sebagaimana adanya. Dalam penelitian ini akan diteliti mengenai perlindungan pasien sebagai konsumen jasa bidang meis dalam KUHPerdata, serta bentuk perlindungannya. Pendekatan Penelitian yang dipakai dalam penelitian hukum diantaranya: Pendekatan perundang - undangan (statue approach), Pendekatan kasus (case approach), Pendekatan historis (bistorical approach), Pendekatan perbandingan (comparative approach), Pendekatan konseptual (conceptual approach). Penelitian ini akan menggunakan pendekatan konseptual (conceptual approach). mengenai masalah masalah penegakan perlindungan pasien serta digunakan pendekatan perundang- undangan (statue approach) terutama pengaturan dalam KUHPer dan Undang - Undang yang mengatur perlindungan konsumen sebagai instrument hukumnya. Jenis Data digunakan dalam penulisan hukum ini adalah data sekunder yaitu data yang diperoleh dari bahan pustaka berupa keterangan - keterangan yang secara tidak langsung diperoleh melalui studi kepustakaan, bahan - bahan dokumenter, tulisan - tulisan ilmiah dan sumber - sumber tertulis lainnya. Sumber data penelitian hukum ini, dipergunakan jenis data sekunder, yang dari sudut kekuatan mengikatnya 
digolongkan ke dalam beberapa sumber data, yaitu : bahan hukum primer adalah bahan hukum yang dikeluarkan oleh pemerintah dan bersifat mengikat berupa peraturan perundang - undangan, perjanjian Internasional dalam bentuk traktat dan konvensi yang dalam hal ini berupa KUHPer, UU No.23 tahun 1992 tentang Kesehatan, UU No.8 tahun 1999 tentang perlindungan konsumen dan UU lainnya; bahan hukum sekunder adalah bahan yang memberikan penjelasan mengenai bahan hukum primer, seperti hasil ilmiah para sarjana, hasil penelitian, buku - buku, koran, majalah, dokumen - dokumen terkait, internet, dan makalah, yang dalam penelitian ini peneliti menggunakan literatur yang berhubungan dengan hukum perdata, hukum, perlindungan konsumen khususnya pasien, dan hukum kesehatan; bahan hukum tersier, yakni bahan hukum yang bersifat menunjang bahan hukum primer dan sekunder yang berupa kamus bahasa Indonesia, ensiklopedia bidang kesehatan dan indeks kumulatif.

\section{Teknik Pengumpulan Data}

Kegiatan yang akan dilakukan dalam pengumpulan data dalam penelitian ini yaitu Studi Pustaka dengan cara identifikasi isi. Alat pengumpulan data dengan mengidentifikasi isi dari data sekunder diperoleh dengan cara membaca, mengkaji, dan mempelajari bahan pustaka baik berupa peraturan perundang undangan, artikel, dari internet, makalah seminar nasional, jurnal, dokumen, dan data - data lain yang mempunyai kaitan dengan data penelitian ini.

Agar data yang dikumpulkan dapat dipertanggungjawabkan, dan dapat menghasilkan jawaban yang tepat dari suatu permasalahan, maka perlu suatu teknik analisa data yang tepat. Analisis data merupakan langkah selanjutnya untuk mengolah hasil penelitian menjadi suatu laporan. Teknik analisis data adalah proses mengorganisasikan dan mengurutkan data ke dalam pola, kategori, dan satuan pola sehingga dapat ditentukan dengan tema dan dapat dirumuskan hipotesis kerja seperti yang disarankan oleh data.

Teknik analisis data yang digunakan dalam penelitian hukum ini menggunakan pola pikir / logika induktif, yaitu pola pikir untuk menarik kesimpulan dari kasus - kasus individual nyata menjadi kesimpulan yang bersifat umum. Pada dasarnya pengolahan dan analisis data bergantung pada jenis datanya. Pada penelitian hukum berjenis normatif, maka dalam mengolah dan menganalisis bahan hukum primer, bahan hukum sekunder dan bahan hukum tersier tidak dapat lepas dari berbagai penafsiran hukum yang dikenal dalam ilmu hukum.

\section{PEMBAHASAN}

Tenaga Kesehatan yang diberikan kepercayaan penuh oleh pasien, haruslah memperhatikan baik buruknya tindakan dan selalu berhati-hati di dalam melaksanakan tindakan medis, dengan tujuan agar perlindungan terhadap pasien dapat terealisasikan Dari tindakan medis tersebut tidak menutup kemungkinan terjadi suatu kesalahan ataupun kelalaian. Kesalahan ataupun kelalaian yang dilakukan tenaga kesehatan dalam melaksanakan tugas profesinya dapat berakibat fatal baik terhadap badan maupun jiwa dari pasiennya, dan hal ini tentu saja sangat merugikan bagi pihak pasien. Salah satu realita tentang kurang adanya perlindungan terhadap pasien dapat digambarkan dalam kasus yang dialami oleh salah satu keluarga di daerah B. Penggugatnya yaitu sepasang suami istri, istri mengandung anak pertama dan pemeriksaan di Rumah Bersalin B menyatakan kondisi bayi dan ibunya sehat, tidak ada kelainan apapun. Pemeriksaan itu diawasi oleh seorang dokter yang bertugas di sana. Suatu ketika istri tersebut merasa sakit pada perut seperti gejala akan melahirkan, kemudian suami membawa istrinya ke Rumah Bersalin B.

Tak lama kemudian salah satu bidan memeriksa detak jantung bayi dan memberi petunjuk tentang cara bernafas saat akan melahirkan. Selang waktu tiga puluh menit, ada telepon masuk dari handphone bidan ternyata ada pasien mau melahirkan di klinik milik bidan tersebut. Bidan tersebut meninggalkan pasiennya untuk memberikan pengarahan kepada asistenya yang dikliniknya sendiri, dengan kata lain bahwa bidan tersebut merangkap pekerjaan sebagai karyawan rumah sakit bersalin dan sebagai bidan di kliniknya sendiri.

Setelah beberapa lama bidan kembali kemudian melakukan pemecahan ketuban. Saat ketuban pecah, bidan merasa binggung dan panik, setelah itu bidan menyuruh sang 
suami untuk membawa istrinya ke RSUD setempat.

Atas suruhan bidan tersebut, sang suami langsung membawa istrinya ke RSUD setempat tanpa didampingi bidan yang menangani istrinya tersebut. Setiba di RS, sang istri ditangani oleh tim medis RSUD setempat, dan melahirkan seorang bayi tetapi dalam keadaan meninggal. Menurut keterangan pihak RSUD, bayi meninggal karena prolaps tali pusar dan kematian sudah dalam kandungan. Karena bidan tidak serius dan berhati- hati dalam menangani pasien, mengakibatkan kematian bayi pasangan suami istri tersebut. Pihak yang harus bertanggung jawab dalam hal ini adalah bidan dan pimpinan Rumah Bersalin yang bertanggung jawab penuh atas aktifitas dari Rumah Bersalin tersebut. Kejadian ini masih sering terjadi di daerah tersebut karena kurangnya pengetahuan medis maupun secara hukum.

Gambaran realisasi perlindungan terhadap pasien melalui contoh kasus diatas, mendorong penulis untuk mengkaji lebih dalam mengenai penegakan perlindungan pasien yang tumbuh dan berkembang di kalangan dunia medis khususnya dalam konteks pelayanan medis.

\section{KESIMPULAN}

1. Bahwa perlindungan hukum terhadap pasien diatur di dalam KUHPerdata Pasal 1320 dalam hal syarat pembuatan perjanjian, 1338 mengenai asas kebebasan berkontrak yaitu perjanjian yang dibuat dan sah akan mengikat para pihak yang terkait, sehingga perjanjian tersebut mengikat hak dan kewajiban pihak- pihak yang terkait, yaitu dokter dengan pasien, 1365 mengenai alasan penuntutan ganti rugi pasien, 1366 mengenai pertanggungjawaban karena kelalaian dalam hal ini kelalaian tenaga medis, 1367 mengenai pertanggungjawaban karena orang yang menjadi tanggungan, dan undangundang sebagai pelengkap seperti, UU No. 23/ tahun 1992 Tentang Kesehatan, UU No. 8 Tahun 1999 tentang Perlindungan Konsumen dan UU No. 29 tahun 2004 tentang Praktek Kedokteran.

2. Bentuk bentuk penyimpangan perjanjian antara dokter dengan pasien yang dapat merugikan pasien adalah wanprestasi atau perbuatan melawan hukum yang dilakukan oleh dokter. Kerugian yang diderita pasien dapat berupa kerugian materiil maupun inmateriil. Bentuk perlindungan pasien dapat berupa suatu pertanggungjawaban dari dokter (pihak yang merugikan pasien). Tanggung jawab hukum dokter terhadap pasien dalam upaya pelayanan medis sebagai berikut :

a. Tanggung jawab etik yaitu yang menyangkut moral profesi yang terangkum dalam Lafal Sumpah Dokter dan dijabarkan dalam Kode Etik Kedokteran Indonesia.

b. Tanggung Jawab Profesi yaitu tanggung jawab yang berkaitan dengan profesi dokter yang menyangkut kemampuan dan keahlian dokter dalam menjalankan tugas profesinya.

c. Tanggung jawab hukum yang berkaitan dengan pasien/ konsumen jasa medis, diantaranya :

1) Tanggung jawab hukum perdata dokter kepada pasien karena wanprestasi terkait dengan syarat sahnya suatu perjanjian yang diatur dalam Pasal 1320 Kitab Undang-Undang Hukum Perdata

2) Tanggung jawab hukum perdata dokter karena perbuatan melawan hukum (onrechtmatige daad) yang diatur dalam Pasal 1365, 1366, 1367 Kitab Undang-Undang Hukum Perdata, yaitu bahwa dokter harus bertanggung jawab atas kesalahannya yang merugikan pasien dan untuk mengganti kerugian, selain itu dokter harus bertanggung jawab atas kerugian yang disebabkan oleh kelalaian dan kurang hati-hati dalam menjalankan tugas profesionalnya serta dokter harus bertanggung jawab terhadap kesalahan yang dilakukan oleh bawahannya yang atas perintahnya melakukan perbuatan tersebut. 


\section{E. DAFTAR PUSTAKA}

Chrisdiono, M. Achadiat. 2000. PernikPernik Hukum Kedokteran. Jakarta: Widya Medika.

Eddie. I. Doloksaribu. Desember 2008. Kendala Pembuktian Dalam Kasus Malpraktek Di Indonesia. Jurnal Gloria Juris Vol.8, No.3.

Gunawan Widjaya. 2000. Hukum Tentang Perlindungan Konsumen. Jakarta: PT. Gramedia Pustaka Utama.

Gunawan. 1991. Memahami Etika Kedokteran. Yogyakarta : Kanisius Guwandi J. 1991. Dokter dan Rumah Sakit. FK UI, Jakarta.

H.Malayu,S.P. Hasibuan. 2001. Pelayananan Terhadap Konsumen Jasa. Jakarta: PT. Bumi Aksara.

Hermien Hadiati K. 1984. Hukum dan Masalab Medik. Surabaya : Erlangga University Press.

Indriyanti Dewi, Alexsandra,S.H.,M.Hum. 2008. Etika dan Hukum Kesehatan. Yogyakarta : Pustaka Book Publisher.

Johan Nasution, Bahder. 2005. Hukum Kesehatan Pertanggungjawaban Dokter. Jakarta: PT. Rineka Cipta.

Jhonny Ibrahim. 2006. Teori dan Metodologi : Penelitian Hukum Normatif. Malang : Bayumedia Publishng.

Jusuf Hanifah. 2001. Etika Kedokteran dan Hukum Kesehatan. Jakarta: Kedokteran ECG.

Kitab Undang-Undang Hukum Perdata (KUH Perdata).

Leenen dan Lamintang. 1991. Pelayanan Kesehatan dan Hukum. Bandung: Bina Cipta.

Munir Fuady. 2007. Hukum Kontrak Dari Sudut Hukum Bisnis. Bandung: PT. Citra Aditya Bakti.
Nila Ismani. 2001. Etika Keperawatan. Jakarta : Widya Medika. Peter Mahmud Marzuki. 2006. Penelitian Hukum. Jakarta: Kencana.

PP RI No. 32 Tahun 1996 Tentang Tenaga Kesehatan.

Soerjono Soekanto. 2005. Pengantar Hukum Kesebatan. Bandung: CV.Ramadya Karya.

Subekti. 2003. Pokok-Pokok Hukum Perdata. Jakarta: Intermasa. Sudikno Mertokusumo. 1986. Mengenal Hukum.Yogyakarta : Liberty.

Undang-Undang Republik Indonesia No.23 Tahun $1992 \quad$ Tentang Kesehatan.

Undang-Undang Republik Indonesia No.8 Tahun $1999 \quad$ Tentang Perlindungan Konsumen. Undang-Undang Republik Indonesia No.29 Tahun 2004 Tentang Praktek Kedokteran.

Wila Chandrawila Supriadi. 2001. Hukum Kedokteran. Jakarta: CV.Mandar Maju. Wirjono Prodjodikoro.1992. Perbuatan Melawan Hukum. Bandung: Sumur. 